\title{
The human superior tarsal muscle (Müller's muscle): a morphological classification with surgical correlations
}

\author{
Vanderson Esperidião-Antonio · Fátima Conceição-Silva • \\ Bernardo De-Ary-Pires · Mário Ary Pires-Neto • \\ Ricardo de Ary-Pires
}

Received: 13 January 2009/ Accepted: 17 March 2009/Published online: 17 April 2009

(C) Japanese Association of Anatomists 2009

\begin{abstract}
The superior tarsal muscle (STM) is a smooth muscle that originates from the undersurface of the levator palpebrae superioris muscle (LPSM) and inserts onto the superior tarsal plate (STP) of the upper eyelid. We have performed a morphometrical investigation of the STM in 49 adult human cadavers ( 34 males, 15 females). Histological analysis has shown a transitional area between the skeletal striated muscle (LPSM) and the adjacent smooth muscle (STM). We propose an original morphological classification based upon the attachment of STM to the upper border of the STP. Accordingly, we describe four patterns of STM. Pattern 1 (P1) consists of STM attachment to the central portion of the STP. Pattern 2 consists of both medial (P2M) STM attachment to both the central and medial regions of the STP and lateral (P2L) STM attachment to both the central and lateral regions of the STP. Pattern 3 (P3) consists of STM attachment along the whole extent of the STP. Pattern 3 was the most frequently observed pattern $(63.27 \%)$ followed by patterns P2M (24.49\%), P2L $(8.16 \%)$ and P1 $(4.08 \%)$. P3 was the predominant pattern in males $(73.52 \%)$, while in females, both patterns P2M (46.66\%) and P3 (40.00\%) were equally prevalent. The analysis of paired specimens revealed a
\end{abstract}

V. Esperidião-Antonio · B. De-Ary-Pires .

M. A. Pires-Neto $\cdot$ R. de Ary-Pires $(\square)$

Instituto de Ciências Biomédicas, Centro de Ciências da Saúde, Universidade Federal do Rio de Janeiro (UFRJ), CCS, Bloco F,

Cidade Universitária, Rio de Janeiro 21941-590, Brazil

e-mail: arypires@rionet.com.br; arypires@neuroanatomia.org

V. Esperidião-Antonio

Faculdade de Medicina, UNIFESO, Teresópolis, Brazil

F. Conceição-Silva

Instituto Oswaldo Cruz, Fiocruz, Rio de Janeiro, Brazil symmetrical arrangement in $72.20 \%$ of all cases, with the remaining cases $(27.80 \%)$ displaying left-right STM asymmetries. To the best of our knowledge, this is the first description of the STM asymmetries in the medical literature. This innovative classification provides anatomical parameters for interpreting morphological variations of the STM with relevant applications in both plastic surgery and ophthalmology.

Keywords Blepharoplasty $\cdot$ Blepharoptosis .

Morphometry · Müller's muscle · Superior tarsal muscle

\section{Introduction}

The superior tarsal muscle (STM), also known as Müller's muscle, is a smooth muscle adjoining the levator palpebrae superioris muscle (LPSM) that helps raise the upper eyelid. It originates on the underside of the LPSM and inserts onto the superior tarsal plate (STP) of the eyelid. The STM receives its innervation from the sympathetic nervous system arising from fibers that enter the cranial skull base encircling the carotid artery (pericarotid plexus), then traverse ventrally the cavernous sinus, and access the orbit wherein the nerve fibers form a tight plexus around the ophthalmic artery. These postganglionic sympathetic fibers originate in the superior sympathetic cervical ganglion. The STM acts synergistically with the LPSM to raise the upper eyelid. Damage to some elements of the sympathetic nervous system can inhibit this muscle, causing a drooping eyelid phenomenon (blepharoptosis).

The anatomy of the STM and eyelid drooping have long been associated with a neurological condition determined by a sympathetic lesion, often designated as the Horner's syndrome. In 1727, the French physician François Porfour 
du Petit described for the first time (referred to in Aouba et al. 2003) an irritative sympathetic syndrome experimentally observed in dogs that had endured cervical lesions. The Horner's syndrome was first described in humans by the British physician Edward Selleck who reported clinical signs in a patient suffering from a cervical neoplasia (Selleck 1839). Claude Bernard subsequently identified a clinical condition that affected both pupillary contraction and the opening of the rima palpebralis. In 1869, the Swiss ophthalmologist Johann Friedrich Horner contributed important confirmatory clinical findings. This association gave origin to a well-known clinical condition, the Claude Bernard-Horner syndrome, which was shortened to the Horner's syndrome (Bernard 1858; Horner 1869). The Horner's syndrome is generally associated with a structural lesion in the cervical sympathetic nervous chain (autonomic nervous system), and its main clinical signs are upper eyelid ptosis, miosis, enophthalmos and anhydrosis on the face ipsilaterally to the lesion (Myles and Maxner 1994; Walton and Buono 2003). It was Heinrich Müller in 1858 who first described the STM as a small muscle composed of thin fibers of smooth muscular tissue. He described the STM as originating from the belly of the LPSM, posterior to its aponeurosis, and attached to the upper border of the STP (Müller 1858, 1872). This finding became a major anatomical basis for its clinical correlation with the Horner's syndrome.

Surgeries for the correction of dysfunctions in the elevation of the upper eyelid usually incise the STM along with the LPSM (Shields and Putterman 2003), although some case reports have shown unsuccessful results using similar surgical techniques (Ben Simon et al. 2005). We have analyzed some of the patterns of anatomical variations involving the human STM and, based upon our morphometrical analyses of carefully dissected specimens, we propose an original morphological classification of the STM. Here, we report significant differences and asymmetries in the attachment of the STM to the STP that may contribute to improving surgical procedures currently used both in plastic surgery and ophthalmology, mainly for the treatment of blepharoptosis and exophthalmos. Such variants of the human STM should be carefully considered during surgical procedures and also in diagnostic computed tomography (CT) and magnetic resonance imaging (MRI) scans of the upper eyelid region.

\section{Materials and methods}

This investigation was performed in strict accordance with the Bioethical Committee of the National Academy of Medicine (Brazil) and the Bioethical Committee of the National Institutes of Health (NIH, Bethesda, MD). All morphological terminology is in full agreement with the Nomina Anatomica (Terminologica 1998).

Anatomical dissections were performed in 49 orbital regions of adult human cadavers (15 females, 34 males) from the Federal University of Rio de Janeiro (UFRJ, Brazil) and from the Serra dos Orgãos Foundation University (UNIFESO, Brazil). Of the 49 orbital regions examined, 18 were paired structures obtained from the same cadavers $(n=36)$, and 13 were isolated orbits $(n=13)$ resulting from cleaved specimens and involving either right or left hemifaces. The vascular bed of the cadavers was injected with a $10 \%$ formaldehyde solution (Merck, Whitehouse Station, NJ). In order to analyze the morphology of the STM, we performed systematic dissections of the orbital region. External morphometry of the STM and anthropometric reference points were marked according to a morphometrical methodology (Mandarim-de-Lacerda 1995). Dissections were performed both macroscopically and under a surgical microscope using magnifications that varied from 6 to $40 \times$ (DFV-A100 model; D. F. Vasconcellos Optical Instruments, Sao Paulo, Brazil). All measurements were performed with precision calipers (0.05 mm; Mitutoyo, Japan), and the dissected regions were documented photographically (Sony Cybershot-Zeiss DSC-H1, Germany). Linear and angular measurements were processed with an image analysis software (Image Pro Plus v.4.5; Media Cybernetics, Silver Spring, MD). The resulting data were analyzed with a statistical program (SPSS 11.0 for Windows; SPSS, Chicago, IL). Statistical analysis consisted of both parametric and nonparametric tests after appropriate consideration of the normality and homoscedasticity (homogeneity of variance) of the sample groups. In most cases, bivariate analysis of variance was followed by univariate analysis of variance. The Duncan multiple-range "post hoc" test was used to compare groups $(P<0.01)$. Schematic drawings of the STM were made in order to clarify some of the morphological patterns of this smooth muscle of the upper eyelid.

The following STM morphometrical data were studied: (1) tarsal attachment index (TAI), which relates the extension of muscle attachment to the superior tarsal border (in percentage); (2) interangular tarsal distance (ITD), which measures the distance between the eyelid's canthi (in centimeters); (3) maximum tarsal height (MTH), which evaluates the largest tarsal height (in centimeters); (4) muscular divergence index (MDI), which measures the divergence of STM in relation to the upper tarsal border (in degrees); (5) maximum muscular height (MMH), which measures the STM height at the point of maximum convexity of the tarsus (in centimeters); (6) divergence angle (DA), which evaluates the angle of divergence of the STM using the direction of muscular fibers as a reference, starting from the lateral margins of the muscle (in degrees). 
The angular measurements, considered as angles of attachment, were those values obtained by the calculation of the DA. Results are expressed in mean values \pm standard deviation (SD).

Anatomical dissections of the human superior tarsal muscle

Supraorbital incisions were made through the skin, subcutaneous tissue and the frontal bellies of the epicranius muscle. Once those anatomic planes were reflected, the periorbital muscles, the ocular globe and the adjoining structures were carefully dissected. Orbital structures were identified, such as the LPSM and its aponeurosis, extraocular muscles, the superior tarsus, lachrymal gland, adipose tissue, vessels and nerves. The limits of the dissection were determined as follows: laterally, the lateral palpebral ligament; medially, the medial palpebral ligament; posteriorly, a tendinous ring (Zinn's ring). Periorbital fat was meticulously removed. The aponeurosis of the LPSM was then detached from its distal insertion at the anterior aspect of the tarsal plate, fully exposing the STM.

Histological analysis of the superior tarsal muscle

In order to provide an adequate structural context, we removed fragments of the superior tarsus from the middle third of the upper eyelids (right and left) for histological examination. None of the eyelids showed any macroscopic evidence of pathological compromise. All tissue was postfixed for 1 week in $10 \%$ neutral buffered saline, dehydrated in a graded alcohol series, cleared in xylene and embedded in paraffin wax. After histological processing, serial sagittal sections of each eyelid were cut at a thickness of $8 \mu \mathrm{m}$. Two sections were mounted on each of 50 slides at two sample points that were at least $2 \mathrm{~mm}$ apart in the central region of the block and treated with Gomori's trichrome staining (Sigma-Aldrich, St. Louis, MO) following a standard histological technique.

\section{Results}

The STM and the LPSM as well as their anatomical relationship is shown in the upper eyelid region (Fig. 1a, b).

The histological analysis of the muscles in the palpebral region (stained with Gomori's trichrome solution) revealed an area of transition from the striated skeletal muscle (LPSM) to the adjoining smooth muscle (STM) (Fig. 2). A gradual transition between the two muscles is observed. Muscular fibers of both muscles are interspersed with connective tissue. It was also possible to observe the
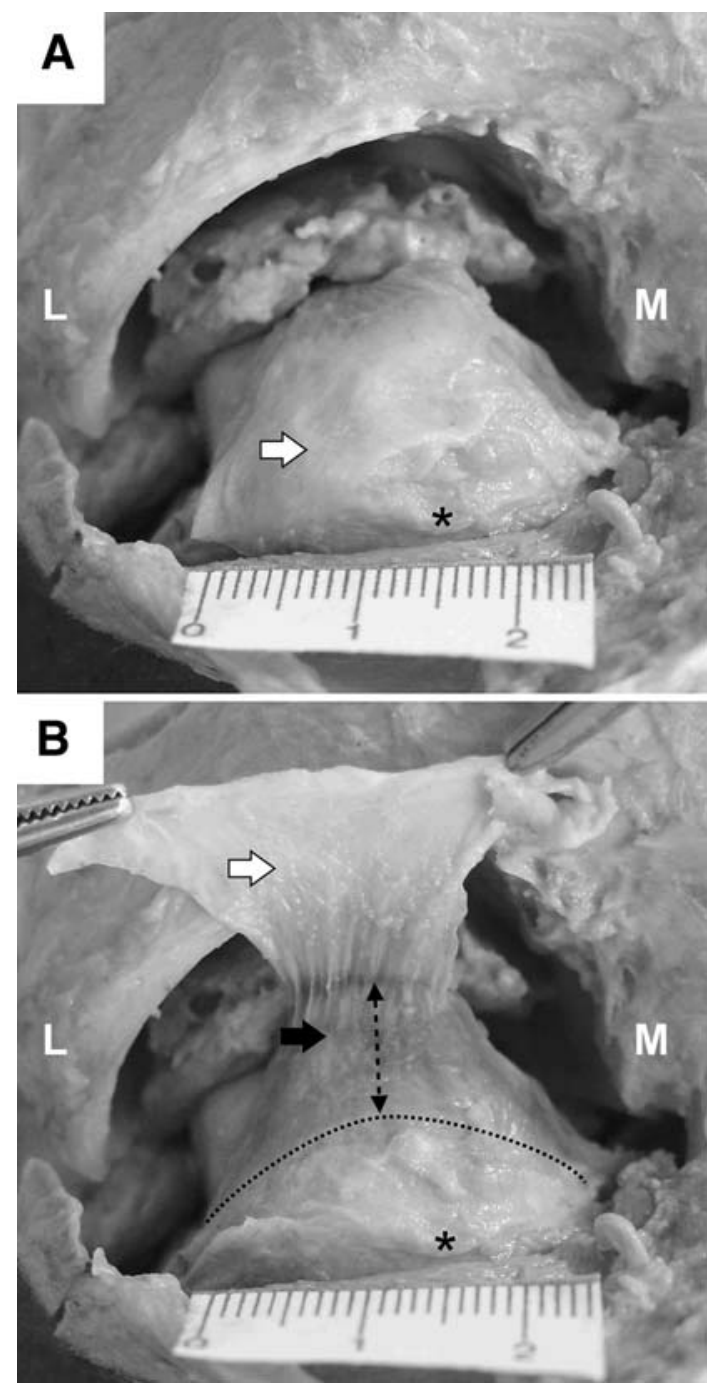

Fig. 1 Anterior dissection of the superior eyelid. a Levator palpebrae superioris muscle (LPSM) and its aponeurosis (large white arrow) extend to the upper tarsal plate. The free margin of the upper eyelid is marked by a black asterisk in both the $\mathbf{a}$ and $\mathbf{b}$ images. $L$ Lateral, $M$ medial. b The LPSM and its aponeurosis have been carefully dissected upwards (large white arrow) unveiling the superior tarsal muscle (STM) located in a deeper layer (large black arrow). Doubleheaded dashed arrow shows STM extending from the undersurface of the LPSM to the superior margin of the superior tarsal plate (dotted tracing). Calibration rulers (in centimeters) are shown in $\mathbf{a}$ and $\mathbf{b}$

presence of true bridges of loose connective tissue joining the anterior aspect of the STM and the posterior aspect of the LPSM. We did not detect any cartilaginous tissue in the STP (superior tarsus).

Anatomical variations of the STM (Müller's muscle) were observed and analyzed in this study. It was possible to distinguish morphological patterns of the STM, both in terms of a variability in their connections to the upper tarsal border as well as in the extension and angle of attachment. Based on these morphological variants, we 


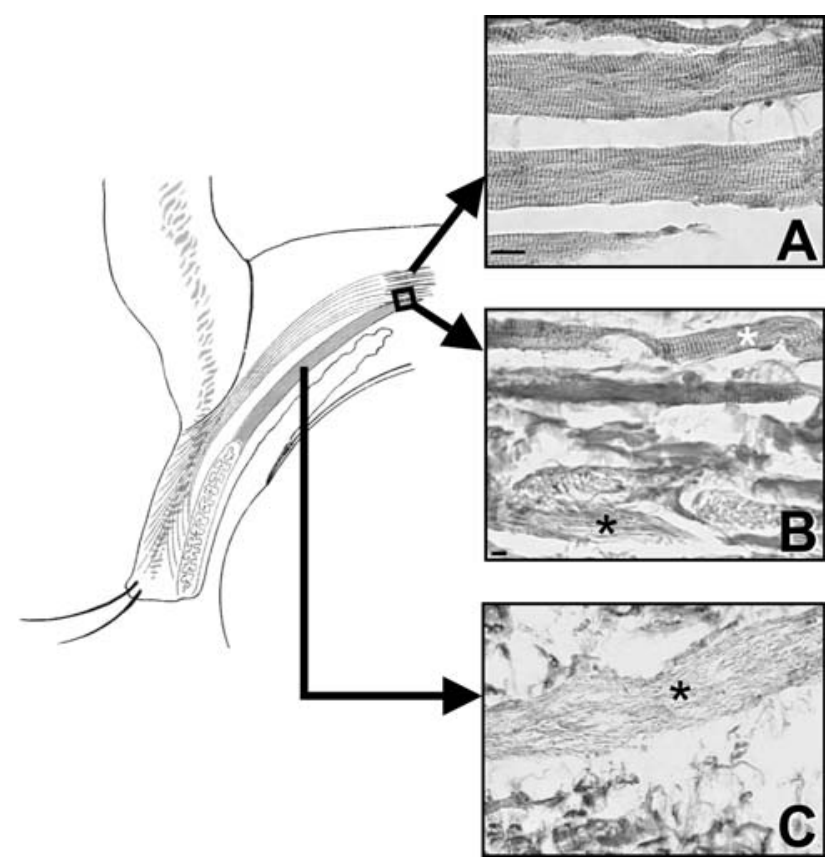

Fig. 2 Histological photographs and schematic representation of an anteroposterior section encompassing the longitudinal axis of the orbit and associated muscles of the superior eyelid. The STM originates from the undersurface of the LPSM muscle (modified from Rouvière 1932). a Striated fibers of the LPSM, b transitional area between the striated fibers of the LPSM (white asterisk) and the smooth fibers of the STM (black asterisk), c smooth fibers of the superior tarsal muscle (black asterisk) forming a separated muscular bundle

propose an anatomical pattern classification of the STM (Müller's muscle) (Fig. 3). Pattern 1 (P1) consists of attachment exclusively onto the central portion of the superior tarsal border; Pattern 2 consists of a medial (P2M) attachment on the central and medial portions of the superior tarsal border, extending as far as the medial palpebral ligament, or a lateral (P2L) attachment onto the central and lateral portions of the superior tarsal border and on the lateral palpebral ligament. Pattern 3 (P3) consists of attachment onto the whole extension of the superior tarsal border, from the medial palpebral ligament to the lateral palpebral ligament.

The classification into four morphological patterns of attachment onto the superior tarsal border showed the following pattern distribution: P3, 31 cases (63.27\%); P2M, 12 cases (24.49\%); P2L, four cases $(8.16 \%)$; P1, two cases $(4.08 \%)$, as shown in Fig. 4 a. Males exhibited a prevalence of pattern 3 (73.52\%) (Fig. 4b), while the distribution in females was polarized between patterns $\mathrm{P} 2 \mathrm{M}$ (46.66\%) and P3 (40\%). Patterns P1 and P2L were less frequent in females, with $6.67 \%$ of cases each (Fig. 4c).

The comparison between left and right orbital regions in the same cadaver ( $n=18$ specimens) showed $72.20 \%$ of cases (13 specimens) with the identical morphometrical
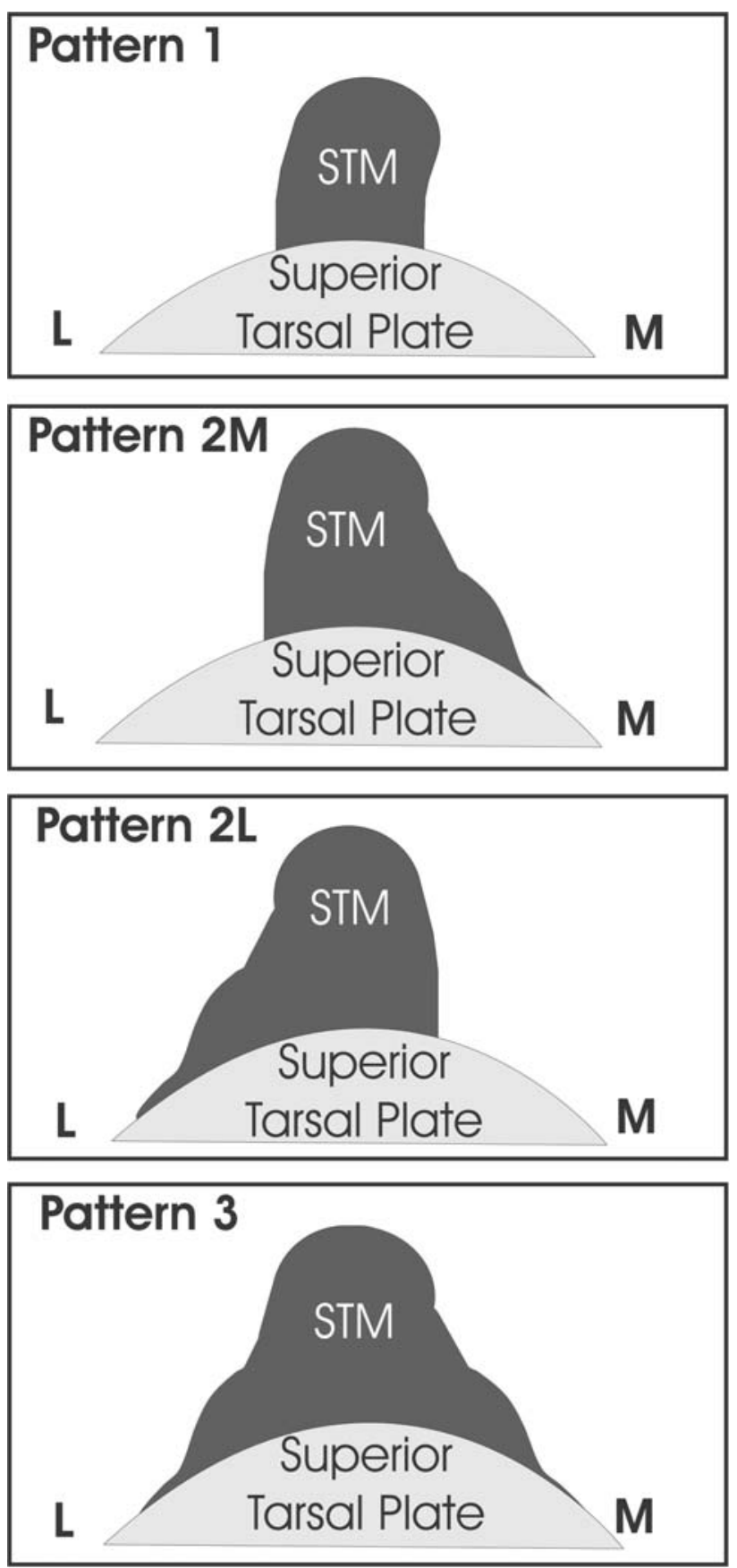

Fig. 3 Schematic patterns of the STM. Pattern 1 (P1) Exclusive attachment to the central segment of the upper margin of the superior tarsus, Pattern 2M (P2M) attachment to the central segment and to the full medial extremity of the superior tarsal plate; Pattern $2 L(\mathrm{P} 2 \mathrm{~L})$ attachment to the central segment and to the full lateral extremity of the superior tarsal plate, Pattern 3 (P3) attachment to the whole extent of the upper margin of the superior tarsal plate. $L$ Lateral, $M$ medial

classification of STM on both sides. The remaining cases (27.80\%, five specimens) displayed left-right STM asymmetrical patterns. The commonest patterns of STM distribution in the specimens considered symmetrical were: (1) $\mathrm{P} 3 / \mathrm{P} 3 \quad(n=10) \quad 76.90 \% ; \quad(2) \quad \mathrm{P} 2 \mathrm{M} / \mathrm{P} 2 \mathrm{M} \quad(n=3)$ 
Fig. 4 Distribution (in percentage) of the anatomical patterns of the superior tarsal muscle. a Total group of individuals studied $(n=49)$, b male individuals $(n=34)$, c female individuals $(n=15)$. Patterns are represented by different tints: P1 black, P2M white, P2L dark gray, P3 light gray

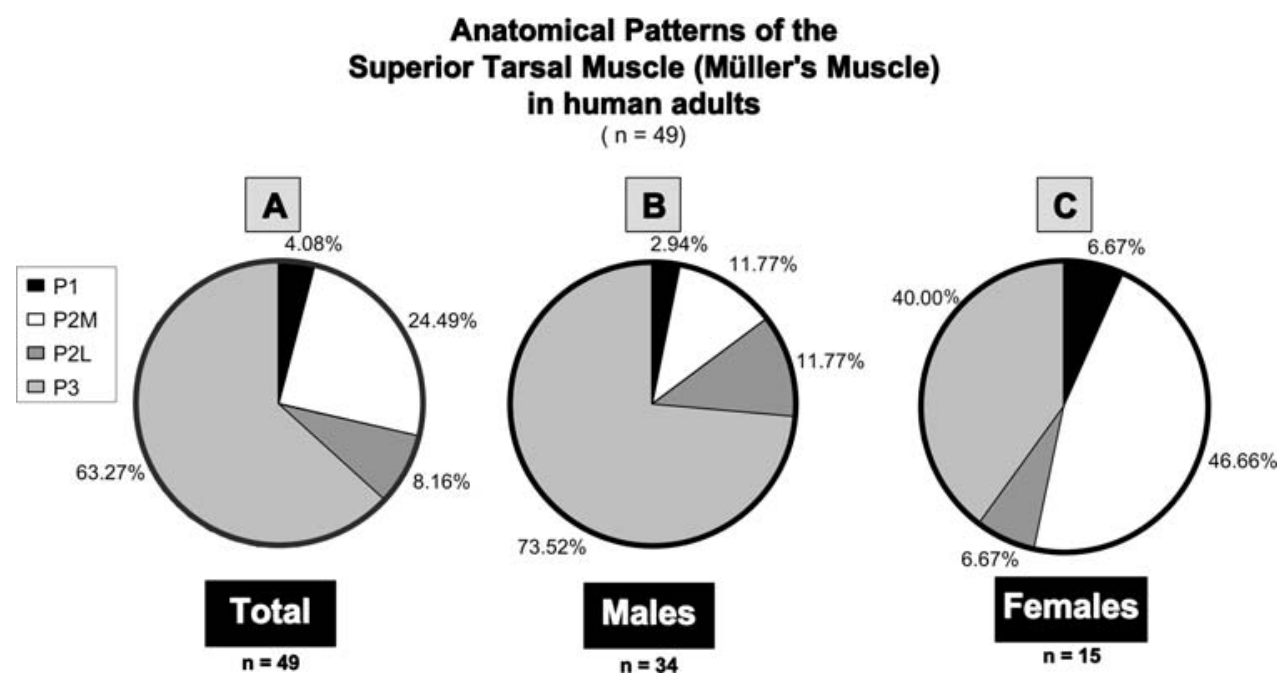

Table 1 Mean values of the morphometric indices in the total sample group and in males and females separately

\begin{tabular}{lccr}
\hline Morphometric indices & Total $(n=49$ specimens) & Males $(n=34$ specimens $)$ & Females $(n=15$ specimens $)$ \\
\hline TAI $(\%)$ & 87.50 & 87.60 & 80.20 \\
IATD $(\mathrm{mm})$ & 23.00 & 22.00 & 23.00 \\
MTH (mm) & 6.60 & 6.90 & 6.50 \\
MDI $\left({ }^{\circ}\right)$ & 57.13 & 58.85 & 56.87 \\
MMH $(\mathrm{mm})$ & 8.10 & 8.20 & 8.10 \\
DA $\left(^{\circ}\right)$ & 45.48 & 43.65 & 48.90
\end{tabular}

TAI Tarsal attachment index, IATD interangular tarsal distance, $M T H$ maximum tarsal height, $M D I$ muscle divergence index, $M M H$ maximum tarsal muscle height, $D A$ superior tarsal muscle divergence angle

$23.10 \%$. The specimens with asymmetrical distribution showed higher variation. The following associations were surmised based on the distribution of morphological patterns: (1) P3/P2L $(n=2) 40.00 \%$; (2) P2M/P2L $(n=1)$ $20.00 \%$; (3) P3/P1 $(n=1) 20.00 \%$; (4) P1/P2M $(n=1)$ $20.00 \%$.

The measurements of the parameters listed in "Materials and methods" were useful to analyze the possibility of significant variations between males and females (Table 1).

\section{Discussion}

We have presented morphometrical data on the STM based on dissected material from 49 orbital regions. Our findings have enabled us to propose an original classification system comprising morphological patterns of the STM based on variations in both the muscle size and the region of muscular insertion onto the STP. These variations were detected on the latero-medial extension of the STM onto the STP. It should be stressed that, differently from previous descriptions found in the scientific literature (Ceisler et al. 1995), the transition from the belly of the STM to the
LPSM and its aponeurosis (Kakizaki et al. 2005) is not well defined at first, but gradually takes place as the two muscles diverge. Histological analysis also revealed a transitional area between the striated skeletal muscle fibers of the LPSM and the smooth muscle fibers of the STM. In addition, we confirmed the absence of cartilaginous tissue in the extracellular matrix of the STP (Milz et al. 2005).

We observed that the morphometric STM pattern distribution varied according to sex. P3 was the most prevalent pattern in men $(73.52 \%)$, followed by $\mathrm{P} 2 \mathrm{M}$ (11.77\%), P2L (11.77\%) and P1 (2.94\%). In women, however, P2M was the most frequent pattern $(46.66 \%)$, followed by P3 (40.00\%), P2L (6.67\%) and P1 (6.67\%). The data also show a tendency towards sexual differences in the linear attachment of the STM to the STP. Further studies involving more cadavers of both sexes may disclose significant STM morphological differences between males and females.

Our comparison of the left and right orbital regions in the same cadaver revealed that in $72.20 \%$ of the cases, both sides had an identical morphometrical classification of STM. The remaining cases $(27.80 \%)$ displayed left-right STM asymmetrical patterns. To the best of our knowledge, 
this is the very first anatomical description of left-right asymmetries with respect to the STM in the scientific literature.

The STM participates actively in opening the eyelid, and a lesion in this muscle produces Horner's syndrome and blepharoptosis. In contrast, its hyperactivity may produce exophthalmia, as seen in hyperthyroidism. The anatomy of the Müller's muscle is directly associated with surgical correction of blepharoptosis-a common complaint of eyelid drooping in which the upper eyelid cannot be fully elevated as occurs in a healthy person (Shields and Putterman 2003; Pak et al. 2006; Patel et al. 2008). The Müller's muscle-conjunctival resection (MMCR) procedure is a technique in which the STM is partially resected and advanced (Morax et al. 2005). It is used to treat upper eyelid ptosis and may be combined with blepharoplasty (Putterman and Urist 1975; Foster et al. 2006; Michels et al. 2007; Georgescu et al. 2008). The Fasanella-Servat procedure was introduced for cases of minimal blepharoptosis with good levator function (Fasanella and Servat 1961). A clinically important piece of data for the diagnosis of blepharoptosis is the margin reflex distance (MRD) that is synonymous of midpupil-to-upper eyelid distance. This index is commonly reported in the oculoplastic literature, and some authors consider that blepharoptosis is present when MRD $<2 \mathrm{~mm}$ (Small and Meyer 2004). Our results can be useful for understanding and treating eyelid ptosis in an appropriate manner, since there may be unsuccessful surgical repairs that largely depend on muscular asymmetries and not on any surgical malpractice.

The STM is a sympathetic innervated muscle mainly involved in the maintenance of the tonus of the raised eyelids, contributing to the final $2 \mathrm{~mm}$ of eyelid elevation. This finding is based on clinical observations of patients with Horner's syndrome who are often said to have a mild ptosis of approximately $2 \mathrm{~mm}$ (Baldwin et al. 2005). The STM has recently been proposed to have a physiological mechanoreceptor role, which would be useful in the correction of eyelid ptosis. Such a physiological role involves both an increase in the reflexive contraction of the levator muscle and a proportional reduction in the contraction of the frontalis muscle (Yuzuriha et al. 2005, 2008). Upper eyelid ptosis commonly occurs due to abnormal functioning of either the LPSM or the STM. Revision of the literature on etiologies responsible for the signs present in the Horner's syndrome revealed a number of diseases specifically associated with Horner's syndrome, such as Pancoast tumor of the lung (Attar et al. 1998), Rowlend-Payne syndrome, caused by mediastinal neuroblastoma (Kapoor et al. 2005), pseudoaneurysm of the internal carotid artery (Mastan 2005), metastatic breast cancer (Kovacic et al. 2007), some congenital lesions (Castillo et al. 2005; Gupta et al. 2005) and metastatic tumor of the cavernous sinus
(Tsuda et al. 2005). Sympathetic fibers with adrenergic receptors alpha-1D, alpha- $2 \mathrm{C}$ and beta- 2 receptors have been documented within human STM, and the alpha- $2 \mathrm{C}$ receptor in particular may play a role in determining the response of the eyelid to phenylephrine (Skibell et al. 2007).

Pathological changes of the STM are well-recognized as being clinically associated with upper eyelid retraction in Graves ophthalmopathy (GO), with a 4:1 female-to-male ratio (Richter et al. 2007). Our results on sexual differences in STM morphological patterns may help explain such a high prevalence of GO in women. We found a predominant STM pattern (P2M 46.66\%) in the orbital regions dissected from female cadavers. It would therefore seem to be physically reasonable to suppose that such STM hyperactivity (observed in P2M pattern) is largely dependent on the application of a muscular force upon a smaller region of the STP. This could generate more pressure and even larger displacement (retraction) of the upper eyelid compared to the P3 pattern, which was found predominantly in the orbital regions dissected from male cadavers $(73.52 \%)$. Patterns of gene expression appear to correlate with the STM histopathological changes in GO (Shih et al. 2006). Interestingly, a graded and controlled excision of the STM, with or without recession of the levator aponeurosis, is an excellent technique for releasing thyroid-related upper eyelid retraction (Putterman 1981; Putterman and Fett 1986; Tremolada and Tremolada 1997).

In conclusion, surgical procedures to correct the rima palpebralis by definition must consider the morphological pattern of STM since the possibility of variation is large and may be associated with difficulties in the correct exploration of the orbital region.

Acknowledgments We are grateful to Demir Mendes, Elden da Motta Cortez, Fábio Rodrigues da Costa and Genaro Amaral de Barros from UFRJ, and to Rogerio Diniz de Carvalho and Genésio Pessoa da Silva from Fundação Educacional Serra dos Órgãos for their excellent technical assistance. We are also grateful to Alexandra Ferreira dos Santos, Antonia Lima Carvalho and Tania Regina Pontes Cordeiro for their help during the organization of this work. This investigation was partly supported by grants from FAPERJ and UNIFESO.

\section{References}

Aouba A, Der Agopian P, Genty-Le Goff I, Mutschler C, Janin N, Patri B (2003) Pourfour du Petit syndrome: a rare aetiology of unilateral exophtalmos with mydriasis and lid retraction. Rev Med Interne 24:261-265

Attar S, Krasna MJ, Sonett JR et al (1998) Superior sulcus (Pancoast) tumor: experience with 105 patients. Ann Thorac Surg 66:193198

Baldwin HC, Bhagey J, Khooshabeh R (2005) Open sky Muller muscle-conjunctival resection in phenylephrine test-negative blepharoptosis patients. Ophthal Plast Reconstr Surg 21:276-280 
Ben Simon GJ, Lee S, Schwarcz RM, McCann JD, Goldberg RA (2005) External levator advancement vs Muller's muscleconjunctival resection for correction of upper eyelid involutional ptosis. Am J Ophthalmol 140:426-432

Bernard C (1858) Leçons sur la physiologie et la pathologie du système nerveux. Faculté de Médicine de Paris 2:473-474

Castillo BV Jr, Khan AM, Gieser R, Shownkeen H (2005) Purtscherlike retinopathy and Horner's syndrome following coil embolization of an intracavernous carotid artery aneurysm. Graefes Arch Clin Exp Ophthalmol 243:60-62

Ceisler EJ, Bilyk JR, Rubin PA, Burks WR, Shore JW (1995) Results of Mullerotomy and levator aponeurosis transposition for the correction of upper eyelid retraction in Graves disease. Ophthalmology 102:483-492

Fasanella RM, Servat J (1961) Levator resection for minimal ptosis: another simplified operation. Arch Ophthalmol 65:493-496

Foster JA, Holck DE, Perry JD et al (2006) Fibrin sealant for Muller muscle-conjunctiva resection ptosis repair. Ophthal Plast Reconstr Surg 22:184-187

Georgescu M, Vagefi M, McMullan, McCann J, Anderson R (2008) Upper eyelid myectomy in blepharospasm with associated apraxia of lid opening. Am J Ophthalmol 145:541-547.e1

Gupta M, Dinakaran S, Chan TK (2005) Congenital Horner syndrome and hemiplegia secondary to carotid dissection. J Pediatr Ophthalmol Strabismus 42:122-124

Horner J (1869) Über eine Form von Ptosis. Klin Monatsbl Augenheilkd 7:193

Kakizaki H, Zako M, Nakano T, Asamoto K, Miyaishi O, Iwaki M (2005) The levator aponeurosis consists of two layers that include smooth muscle. Ophthal Plast Reconstr Surg 21:379382

Kapoor V, Lodha R, Agarwala S (2005) Superior mediastinal syndrome with Rowland-Payne syndrome: an unusual presentation of cervico-mediastinal neuroblastoma. Pediatr Blood Cancer 44:280-282

Kovacic S, Lovrencic-Huzjan A, Drpa G, Hat J, Belina S (2007) Horner's syndrome as an initial sign of metastatic breast cancer: case report. Cancer Detect Prev 31:450-452

Mandarim-De-Lacerda CA (1995) Métodos quantitativos em morfologia. Ed/UERJ, Rio de Janeiro

Mastan M (2005) Carotid artery pseudoaneurysm with Horner's syndrome: delayed complication of internal jugular venous cannulation. Hosp Med 66:314-315

Michels KS, Vagefi MR, Steele E et al (2007) Muller muscleconjunctiva resection to correct ptosis in high-risk patients. Ophthal Plast Reconstr Surg 23:363-366

Milz S, Neufang J, Higashiyama I, Putz R, Benjamin M (2005) An immunohistochemical study of the extracellular matrix of the tarsal plate in the upper eyelid in human beings. J Anat 206:3745

Morax S, Nunes TP, Ben-Ayed H, Hamedani M, Matayoshi S (2005) Evaluation of the surgery results of Muller's muscle-conjunctival resection in the treatment of blepharoptosis. Arq Bras Oftalmol 68:333-337

Müller H (1858) Über einen glatten Muskel in der Augenhöhle des Menschen in der Säugetiere. Z Wiss Zool 9:541

Müller H (1872) Müller's Gesammelte und Hinterlassene Schriften zur Anatomie und Physiologie des Auge. Engelmann, Leipzig
Myles WM, Maxner CE (1994) Localizing value of concurrent sixth nerve paresis and postganglionic Horner's syndrome. Can J Ophthalmol 29:39-42

Pak J, Shields M, Putterman AM (2006) Superior tarsectomy augments super-maximum levator resection in correction of severe blepharoptosis with poor levator function. Ophthalmology 113:1201-1208

Patel SM, Linberg JV, Sivak-Callcott JA, Gunel E (2008) Modified tarsal resection operation for congenital ptosis with fair levator function. Ophthal Plast Reconstr Surg 24:1-6

Putterman AM (1981) Surgical treatment of thyroid-related upper eyelid retraction. Graded Muller's muscle excision and levator recession. Ophthalmology 88:507-512

Putterman AM, Fett DR (1986) Muller's muscle in the treatment of upper eyelid retraction: a 12-year study. Ophthalmic Surg 17:361-367

Putterman AM, Urist MJ (1975) Muller muscle-conjunctiva resection. Technique for treatment of blepharoptosis. Arch Ophthalmol 93:619-623

Richter DF, Stoff A, Olivari N (2007) Transpalpebral decompression of endocrine ophthalmopathy by intraorbital fat removal (Olivari technique): experience and progression after more than 3000 operations over 20 years. Plast Reconstr Surg 120:109-123

Rouvière H (1932) Anatomie des lymphatique de l'homme. Masson et Cie, Paris

Selleck E (1839) An interesting opthalmologic finding in humans with eyelid ptosis. Lond Med Gazette 3:18-38

Shields M, Putterman A (2003) Blepharoptosis correction. Curr Opin Otolaryngol Head Neck Surg 11:261-266

Shih MJ, Liao SL, Kuo KT, Smith TJ, Chuang LM (2006) Molecular pathology of Muller's muscle in Graves' ophthalmopathy. J Clin Endocrinol Metab 91:1159-1167

Skibell BC, Harvey JH, Oestreicher JH et al (2007) Adrenergic receptors in the ptotic human eyelid: correlation with phenylephrine testing and surgical success in ptosis repair. Ophthal Plast Reconstr Surg 23:367-371

Small RG, Meyer DR (2004) Eyelid metrics. Ophthal Plast Reconstr Surg 20:266-267

Terminologica (1998) Federative Committee on Anatomical Terminology. Terminologica anatomica. Thieme, Stuttgart

Tremolada C, Tremolada MA (1997) The "triple technique" for treating stable Graves' ophthalmopathy. Plast Reconstr Surg 100:40-48 (discussion 49-50)

Tsuda H, Ishikawa H, Asayama K, Saito T, Endo S, Mizutani T (2005) Abducens nerve palsy and Horner syndrome due to metastatic tumor in the cavernous sinus. Intern Med 44:644-646

Walton KA, Buono LM (2003) Horner syndrome. Curr Opin Ophthalmol 14:357-363

Yuzuriha S, Matsuo K, Ishigaki Y, Kikuchi N, Kawagishi K, Moriizumi T (2005) Efferent and afferent innervations of Mueller's muscle related to involuntary contraction of the levator muscle: important for avoiding injury during eyelid surgery. Br J Plast Surg 58:42-52

Yuzuriha S, Matsuo K, Hirasawa C, Moriizumi T (2008) Refined distribution of myelinated trigeminal proprioceptive nerve fibres in Mueller's muscle as the mechanoreceptors to induce involuntary reflexive contraction of the levator and frontalis muscles. J Plast Reconstr Aesthet Surg. doi: 10.1016/j.bjps.2008.06.046 